\title{
THE REGIONAL DEVELOPMENT OF THE ROMANIAN RURAL TOURISM SEGTOR
}

\author{
Adriana AnaMaria Davidescu ${ }^{1}$, Vasile Alecsandru Strat ${ }^{2 *}$, Raluca Mariana \\ Grosu $^{3}$, Ion Daniel Zgură ${ }^{4}$ and Sorin Anagnoste ${ }^{5}$ \\ ${ }^{1)}$ The Bucharest University of Economic Studies and National Research Institute \\ for Labour and Social Protection, Romania \\ ${ }^{2334) 5)}$ The Bucharest University of Economic Studies, Romania
}

Please cite this article as:

Davidescu, A.A.M., Strat, V.A., Grosu, R.M., Zgură, I.D. and Anagnoste, S., 2018. The Regional Development of the Romanian Rural Tourism Sector. Amfiteatru Economic, 20(Special No. 12), pp. 854-869.

\section{Article History}

Received: 2 August 2018

Revised: 6 September 2018

Accepted: 1 October 2018

\section{DOI: $10.24818 / \mathrm{EA} / 2018 / \mathrm{S} 12 / 854$}

\begin{abstract}
In the present paper we put forward a clear assessment of the Romanian rural tourism, from a regional perspective. Based on data for 2016, using principal component analysis for mixed data and cluster analysis, we outline an accurate image of the Romanian rural tourism at NUTS level 3, focusing on its main determinants and key regional poles of development. The novelty of the paper lays in developing one of the first composite indices measuring the rural tourism sector, in the Romanian scientific literature, which allows to rank the counties based on their performance and in providing a mapping of rural tourism, highlighting the counties with promising potential for developing activities in this sector. With high practical value, our empirical results may represent an important starting point in developing coherent policies meant at supporting and promoting rural tourism which can become an important generator of wealth and growth in the rural areas of Romania.
\end{abstract}

Keywords: regional development, rural tourism, principal component analysis (PCA), regional disparities, rural Romania

JEL Classification: L83, O18, P25, P48

* Corresponding author, Vasile Alecsandru Strat - vasile.strat@ csie.ase.ro 


\section{Introduction}

An important part of Romania's population (over 40\%) lives in the rural area, as revealed by the latest Eurostat regional yearbook, when referring to the share of the total population by degree of urbanization in 2015 (Eurostat, 2017). The same source ranks Romania amid the European Union (EU) members with the highest percentages of population in rural areas, along with Poland, Denmark, Croatia, Latvia, Hungary, Slovenia, Luxembourg, and Lithuania. This aspect usually generates important social and economic challenges at both national and regional levels, especially when considering that the rural area in Romania is not very developed as the ones in the other EU members.

The fact that in 2015, in Romania, at least half of the rural population was at risk of poverty or social exclusion, over $40 \%$ faced the risk of monetary poverty, and $29 \%$ of the rural population lived in severe material deprivation are just few relevant examples in this sense (Eurostat, 2017). Furthermore, the rural area in Romania faces important challenges, mainly driven by massive emigration. A phenomenon of unprecedented dimensions, the external migration puts a lot of pressure on Romania's economic, social, demographic etc. development. Significant consequences are felt at both national and regional levels, in both rural and urban environments.

Referring only to the rural area, the intensification of the phenomenon over the recent years (especially after Romania became a member of the EU) lead to a massive depopulation of Romanian villages, to school drop-outs from children left behind by their emigrating parents, who were raised by their grandparents or other relatives, to those children involvement in inadequate entourages and activities (Grosu and Dinu, 2016), to the alteration of the 'traditional' norms according to which elderly care falls under the family's responsibility (Thelen, 2015), to poor development of the infrastructure, etc. The negative effects of external migration on Romanian villages are amplified also by the internal migration of residents living in rural areas to urban areas, in search of better socio-economic opportunities. However, emigration to more developed Western countries has also some positive effects on the rural areas in Romania. These are usually associated to remittances, often, easily observed in improved living conditions, especially of those family members left behind by the Romanian emigrants.

In such a context, there is an extreme need for coherent policies and measures meant at developing the rural areas in Romania. These offer various opportunities worth exploring by policy makers/public authorities, public entities, private actors, non-governmental organizations, individuals. Related to the emigration phenomenon, the most adequate measure may be directly connected to returnee entrepreneurship. By attracting back Romanians who have gained important knowledge and skills in various industries they have been working in, during their emigration period - such as tourism (especially hotels and restaurants), agriculture, construction, etc. - and translating their experience and expertise in innovative entrepreneurial ventures may represent an important wealth generator in the rural area, at both economic and social levels (Grosu, 2015; Zamfir, Mocanu and Grigorescu, 2018).

Rural tourism, generally seen as any form of "tourism that takes place in the countryside" (Lane, 1994 cited in Pop, Coros and Balint, 2017, p. 72) is a field that can be properly tapped through returnee entrepreneurship and, managed in a proper way, this might become, probably along with agriculture, an important engine for the economic development of the Romanian rural areas. Its role as a wealth generator is highly acknowledged in the scientific 
literature, especially through its contribution to "creating jobs and increasing income therefore improving the living standards, reducing migration, supporting the protection of natural landscapes and environment, preserving cultural and architectural identities, crafts, traditional lifestyles, increasing and spreading the social contacts and the exchange of knowledge and experiences" (Turnock, 1999; Hall, 2004; Aref and Gill, 2009; Iorio and Corsale, 2013 cited in Pop, Coros and Balint, 2017, p. 73).

In such a context, through this paper, we bring an innovative approach to the Romanian rural tourism sector's complexity assessment, from a regional perspective. Thus, we aim to highlight the main drivers of rural tourism in Romania using the principal component analysis (PCA) for mixed data and to identify the main regional poles of development using the cluster analysis. In this sense, we have structured the paper into three main parts. In the first one, we focus on reviewing the scientific literature specific to the field. In the second part, we explain the research methodology, while in the third one we outline our research's empirical results, focusing on their graphical (maps) representation. We end up the paper with a series of final considerations.

\section{Literature review}

Considered "a form of tourism which includes any tourism activity organized and conducted in the rural area by local population and which exploits the local tourism resources (natural, cultural-historical, human) as well as the tourism endowments and structures, including the pensions and agro-tourism farms" (World Tourism Organization, 1997 cited in Ogarlaci, 2014), rural tourism outlines a series of particularities like: "location in rural area; development of the touristic product in a functional way, based on the features of the rural area and on the traditional character; closeness to nature; tranquillity; sense of continuity and stability, of living a lasting history; the ability to better and closely know the rural place and its residents; the chance to integrate in the rural community during the touristic stay; closely knowing/familiarity with local businesses etc." (Nistoreanu et al., 2003; Nistoreanu, 2007).

Rural Romania offers many places where traditions have been preserved with holiness, villages that respect the ancient customs and traditions, still untouched by civilization, where electricity has been the last form of development, important picturesque places, outstanding religious and cultural heritage, a unique flora and fauna, a rich reserve of mineral and thermal waters, friendly, very welcoming hosts, traditional agri-food products, etc. (Nistoreanu et al., 2003), having a great potential for rural tourism development. On the other hand, its weaknesses are closely linked to poor infrastructure development (transportation, public services, staff training), to not being a priority in policy makers' agenda, to the lack of a coherent national strategy and action plan aiming at developing and promoting rural tourism, lack of extra tourism services for entertainment or recreation, etc. (Ildiko, Radulescu and Bran, 2014). However, the same authors (p. 18) suggest a series of opportunities for developing the rural tourism in Romania, somehow, translated into ways to overcome its weaknesses: "hosting persons living in urban areas who need to recover from various diseases in natural, clean environments; organizing crafting workshops for tourists; developing interactive forms of tourism where tourists may be involved in various activities specific to the rural households, like harvesting, hoeing, etc.; valuing mineral springs with therapeutic effects; developing holiday houses; etc." 
As EU member, Romania benefitted of important support schemes and significant capital infusions in rural tourism. However, its development is still in its incipient phase, far from potential, since the supported projects are mostly individual projects (usually referring to the establishment of bed \& breakfast structures) which do not tap the more important systemic problems, especially those related to the transport infrastructure.

Following the approach identified in Andrei et al. (2014), in the present paper we aim to provide a clear assessment of the rural tourism in Romania, from a regional perspective, at the level of 2016. Andrei et al. (2014) analysed the sustainability of the Romanian rural tourism, identifying the NUTS level 2 and 3 of Romania where the rural tourism trends of development are significantly above the national average. Their empirical results point out significant differences between the eight Romanian development regions (NUTS level 2), in terms of rural tourism: "in the Centre region, the tourist flows are significantly higher than in the other development regions, mostly fuelled by the diverse and well preserved medieval age sights and rural civilization areas; the North-East region, through its monasteries and historical heritage, is an important attraction mostly for religious tourism, but the road infrastructure linking the region with Central and Western Europe is relatively poor, significantly limiting tourist access; benefiting from its proximity to the western border, the North-West region faces important tourist flows; the other five development regions have lower tourist flows, below the national average" (Andrei et al., 2014, pp. 8885-8886), somehow a normal aspect for the capital city region (Bucharest-Ilfov), considering its predominantly urban character.

Similar ideas are also supported by Pascariu and Țigănaşu (2014), who, in the accomplished regions' ranking by aspects related to tourism, sustainability and regional development, place the North East region on the last position, mainly because of its poor infrastructure, despite the multitude of its tourist attractions. However, the methods and indicators proposed by Pascariu and Țigănaşu (2014) do not highlight the tourism potential of the regions.

The analysis of tourism potential at regional level, especially using econometric methods/modelling, is a relatively poor researched topic in the scientific literature. Notable contributions are made by Peypoch and Solonandrasana (2008), Gooroochurn and Sugiyarto (2005), Gritsay et al. (2018) and by Imran and Bhat (2013). Peypoch and Solonandrasana (2008) analyse the efficiency and the productivity in the tourism industry in an innovative manner with the help of an aggregated Luenberger productivity indicator for a group of tourism firms. Gooroochurn and Sugiyarto (2005) present an innovative approach for measuring tourism competitiveness in over 200 countries combining both confirmatory factorial analysis and cluster analysis, highlighting the relevance of human factor and refuting the importance of environmental indicators. Gritsay et al. (2018) developed a system of indicators for the clustering potential in the Omsk tourist region, the Russian Federation rather appreciating that the clustering potential is high and thus highlighting the usefulness of such a system. Imran and Bhat (2013) propose to identify the regions with tourism potential in the Pahalgam region located in Kashmir Valley using specific indicators and composite scores highlighting the usefulness of such an approach for both exploring the type of tourist attraction and for developing the necessary infrastructure. On the other hand, the general or the specific tourism potential of a region, whether it is from Romania or another country, is rather often approached in the literature, but the methods employed for analysis are not very often based on econometric methods/modelling (Mitruţ, Constantin and Gruiescu, 2009; Nestorosk, 2012; Oliveira, 2014). 
The main element of novelty brought by our research is the construction of the first composite indicator measuring the performance of the Romanian rural tourism by combining two (very popular) methods of multidimensional analysis - the PCA for mixed data employed for identifying the main determinants of the rural tourism, respectively the cluster analysis used for identifying the main regional development poles of the field.

\section{Research methodology}

Using both spatial distributions and time series, we outline in the present paper an accurate image of the Romanian rural tourism at county level (NUTS level 3), based on 2016 related data. Using a two-index approach, similar to the one used by UNCTAD to analyse the performance and potential of countries in attracting foreign direct investments (UNCTAD, 2012), we constructed two indices to analyse the performance and potential of Romanian counties in the rural tourism sector. As a first step we constructed a performance index to identify the counties which are important poles of rural tourism (in these counties, the rural tourism has a higher share in the national rural tourism than it has the total tourism of the county in the total national tourism) and the ones with a significantly lower performance. The performance index is measured as a ratio between the share of county's rural overnight stays in national rural overnight stays and the share of county's total overnight stays in national total overnight stays. Secondly, we have constructed a potential index (as a composite index aggregating several individual indicators), using the method developed by Chavent et al. (2017) which combines the PCA for numerical data with the multiple correspondence analysis (MCA) for categorical variables, with the purpose of identifying the counties where lies the greatest potential in developing rural tourism. To obtain the composite index, the main steps indicated by OECD Handbook on Constructing Composite Indicators were followed: "theoretical framework, data selection, imputation of missing data, multivariate analysis, normalization, weighting and aggregation, visualization of the results" (OECD, 2008, p.17). As Nardo et al. (2005) highlighted the importance of normalization of data in case of different measurement units, within the analysis, the numerical indicators have been standardized expressed in z-scores.

The next stage was oriented towards identifying the main drivers of rural tourism. Thereby, we have applied the PCA for mix data, which involves the aggregation of a large number of indicators into fewer - principal components - which represent linear combinations of the original variables, uncorrelated and that will recover much of the variance of the original variables. The selection of the optimal number of components is based on the Kaiser Criteria, selecting only the eigenvalues greater than 1 . To investigate the degree of correlation within the set of indicators, the Cronbach Alpha coefficient (c-alpha) was determined, which is the most common estimate of the internal constancy of elements in a model. Nunnally (1978) suggests 0.7 as an acceptable reliability threshold.

To aggregate the principal components into a single composite index, we have used the proportion of variance recovered by each component in the total variance, recovered by all principal components (Davidescu and Strat, 2014 a, 2014b). Since the index can have positive or negative values, making difficult any interpretation, it was transformed so that it can only take values between 0 and 100 , using the percentile rank, stating that 100 is the best performing and 0 is the worst performing. The SPSS Statistics 20.0 software has been used for the computation of percentile rank. 
Our analysis is based on two data sets:

- a numerical data matrix X1, with 9 variables and 41 units (counties, except Bucharest, the capital city);

- a categorical data matrix X2, with 3 variables and 41 units (counties, except Bucharest, the capital city).

However, considering the impossibility of exclusion from maps, Bucharest will be represented in all maps as the $42^{\text {nd }}$ statistical unit, with a zero value, marking therefore, its insignificance for the displayed results.

The main indicators used in our analysis are highlighted in table no. 1.

Table no. 1: Indicators used in the PCA

\begin{tabular}{|l|c|c|c|}
\hline \multicolumn{1}{|c|}{ Indicator } & Code & Source & Type* \\
\hline The number of rural agro-touristic guesthouses & Var1 & NIS, 2016 & 1 \\
\hline Touristic accommodation capacity of guesthouses & Var2 & NIS, 2016 & 1 \\
\hline Arrivals of tourists accommodated in agro-touristic guesthouses & Var3 & NIS, 2016 & 1 \\
\hline Overnight staying in the agro-touristic guesthouses & Var4 & NIS, 2016 & 1 \\
\hline Ratio of rural population & Var5 & NIS, 2016 & 1 \\
\hline $\begin{array}{l}\text { Number of localities with public sewerage installations in rural } \\
\text { area }\end{array}$ & Var6 & NIS, 2016 & 1 \\
\hline Number of localities with drinking water installation in rural area & Var7 & NIS, 2016 & 1 \\
\hline Number of localities where natural gas is distributed in rural area & Var8 & NIS, 2016 & 1 \\
\hline Number of dwellings stock at the end of the year in rural area & Var9 & NIS, 2016 & 1 \\
\hline The county is crossed by the Carpathian Mountains & Var10 & own work & 0 \\
\hline The county is crossed by the Danube River & Var11 & own work & 0 \\
\hline The county has an airport nearby & Var12 & own work & 0 \\
\hline
\end{tabular}

Note: *0 - Dummy Yes/No (1/0) Variable; 1 - Numerical variable

The properties used in PCA or in MCA to interpret the principal components are also applicable to PCA mix, since the factor scores of the numerical variables are correlations with the principal components as in PCA. The factor scores of the categorical variables are mean values of the (normalized) factor scores of the observations that belong to these levels as in MCA.

The term "squared loading" is generic for numerical and categorical variables. It provides a way of measuring the link between variables (regardless their type) and principal components. If the variable $j$ is numerical, the squared loading is the squared correlation. If this same variable is categorical, the squared loading is the correlation ratio. These two measures vary between 0 and 1 and give an idea of the link between the variable and the principal component. Each principal component is a linear combination of numeric and nonnumeric variables.

Once identified the main drivers of rural tourism, which are the outputs of the PCA, these will represent inputs for the cluster analysis which aims to outline the main regional poles of rural tourism using as distance the Square Euclidian distance and the Ward method as linkage method. 


\section{Empirical results and discussions}

In 2016, the number of rural guesthouses in Romania reached approximatively 2000 units, representing almost $30 \%$ of the total touristic units, while the number of places they provided represented almost $12 \%$ of the total number of available places in touristic units. This is a significantly improved situation compared to 2000, when rural guesthouses were accounting below 500, representing only $12 \%$ of the total touristic units, while their number of places represented below $2 \%$ of the total number of available places. However, even if the number of arrivals and the overnight stays has also increased significantly, rural tourism accounts for under $8 \%$ of the total recorded arrivals or overnight stays in 2016.

The geographical distribution of the rural overnight stays (measured as percentage from all overnight stays, at county level, in 2016) outlines the counties of Mures, Cluj, Bihor, Braila, Constanta, Prahova, and Vaslui as important concentration poles. Considering the NUTS level 2 division, the North-West and the South-East regions are the most representative, through the counties of Bihor and Cluj, respectively Braila and Constanta. The North-South demarcation line represented by the Carpathians is also remarkable, with a general better performance for the Northern counties. (Figure no. 1)

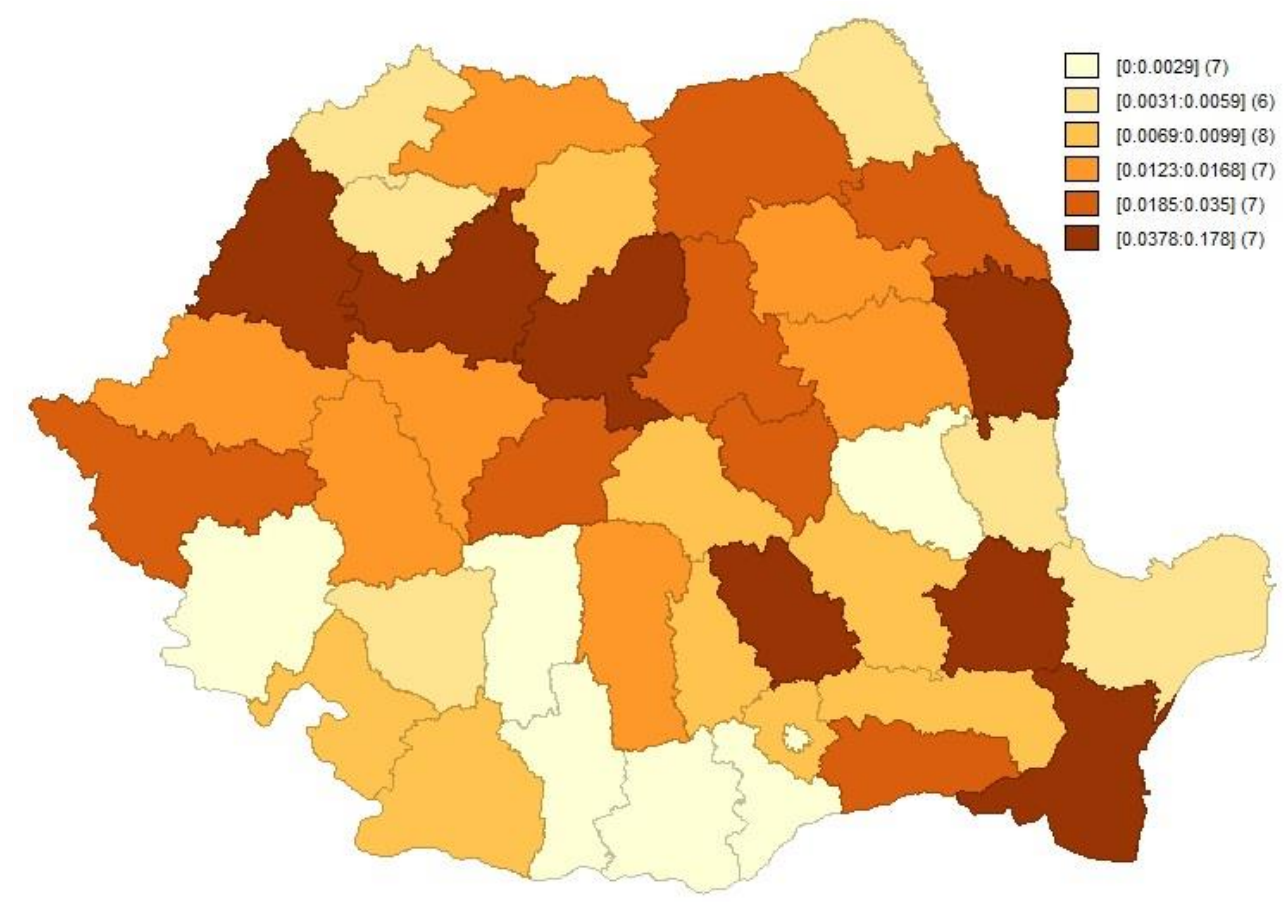

Figure no. 1: Percentage of rural overnight stays from total overnight stays, per county, in 2016

Advancing the study, when analysing the share of rural overnight stays per county in the total rural overnight stays at national level, the concentration of the activity in the North-West region, through Bihor and Cluj counties, is even more obvious. Other concentration poles 
refer to the counties of Sibiu, Harghita, Neamt, Suceava, and Braila. The counties of Sibiu and Harghita support a good presence of the Centre region, while the North-East region is proudly represented by Neamt and Suceava counties. (Figure no. 2)

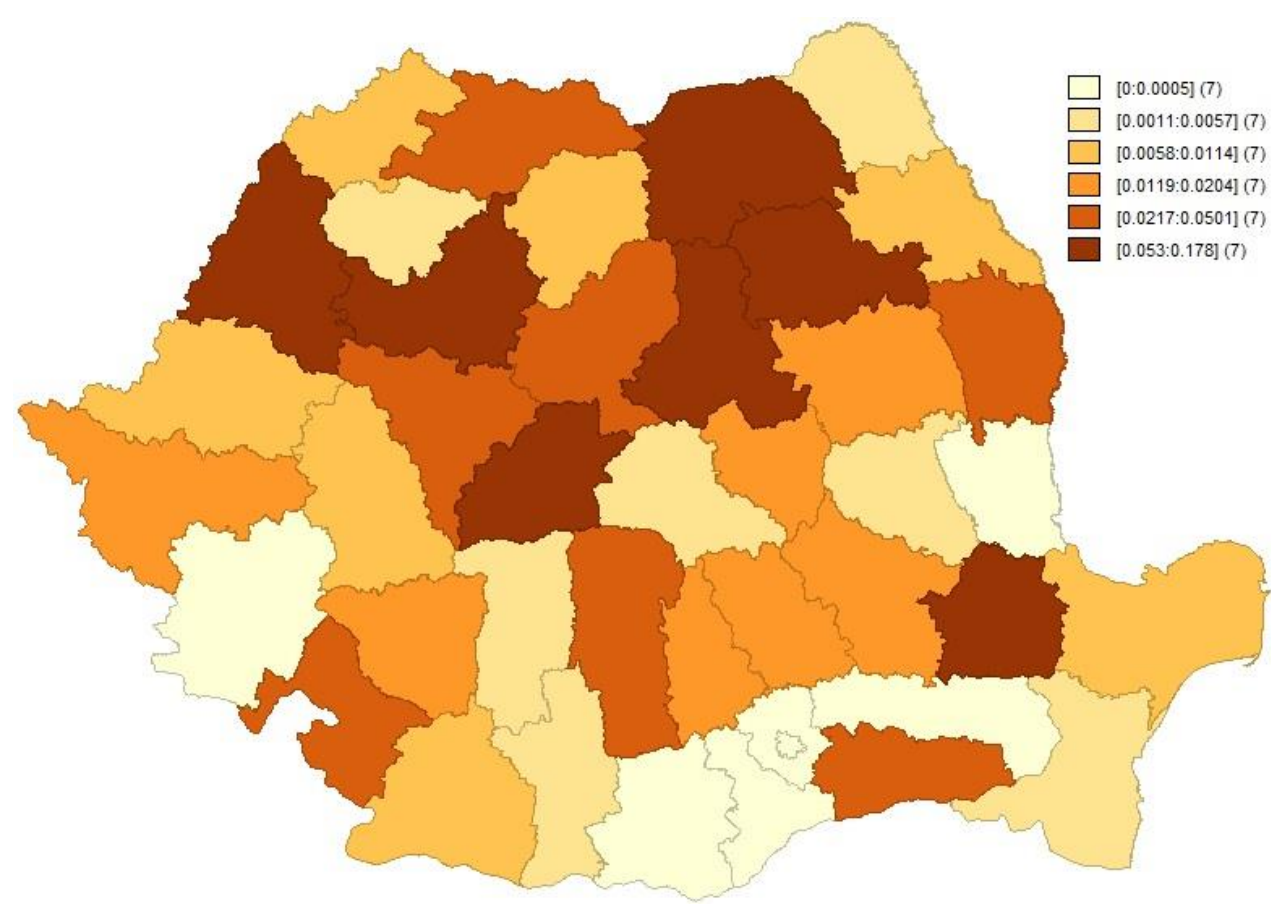

Figure no. 2: Percentage of rural overnight stays per county in total rural overnight stays at national level, in 2016

The general performance of the counties (in 2016) measured through the performance index, as a ratio between their rural tourism sector and the entire tourism sector reveals that the most performant counties are Maramures, Suceava, Neamt, Harghita, Alba, Mehedinti, and Arges. In terms of their NUTS level 2 concentration, the North-East region (counties Suceava and Neamt) and the Centre region (counties Harghita and Alba) are the most representative. However, other performant counties are located along the Carpathians (and in their vicinity), with a few exceptions for the South-Eastern part of the country, respectively: Tulcea, Braila and Calarasi counties (Figure no. 3). Another notable aspect revealed by the performance index is that almost half of the counties (20) have a better performance in the rural tourism sector than in the general tourism sector. (Figure no. 4) 


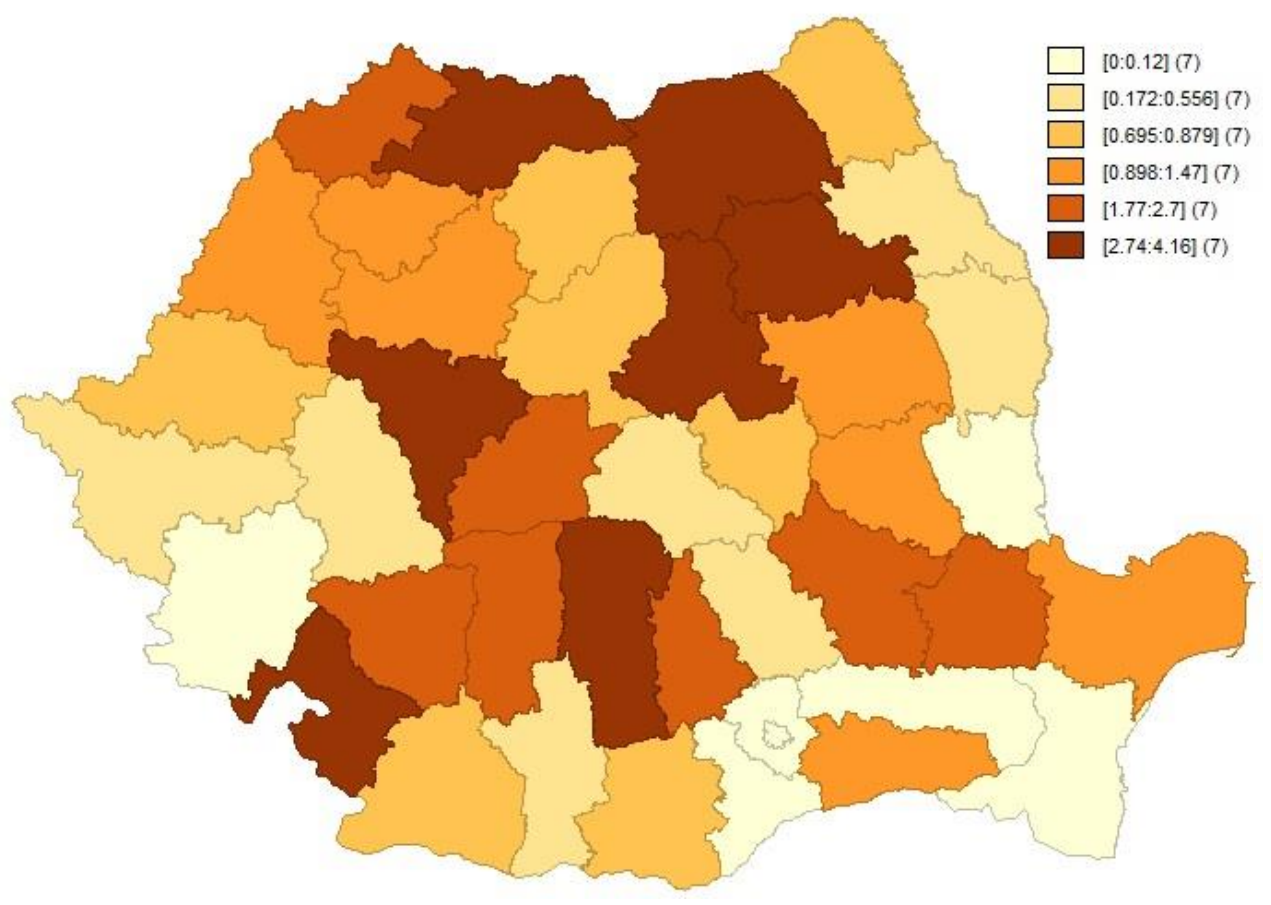

Figure no. 3: Ratio between the percentage of rural overnight stays and the percentage of all overnight stays (county level - year 2016)

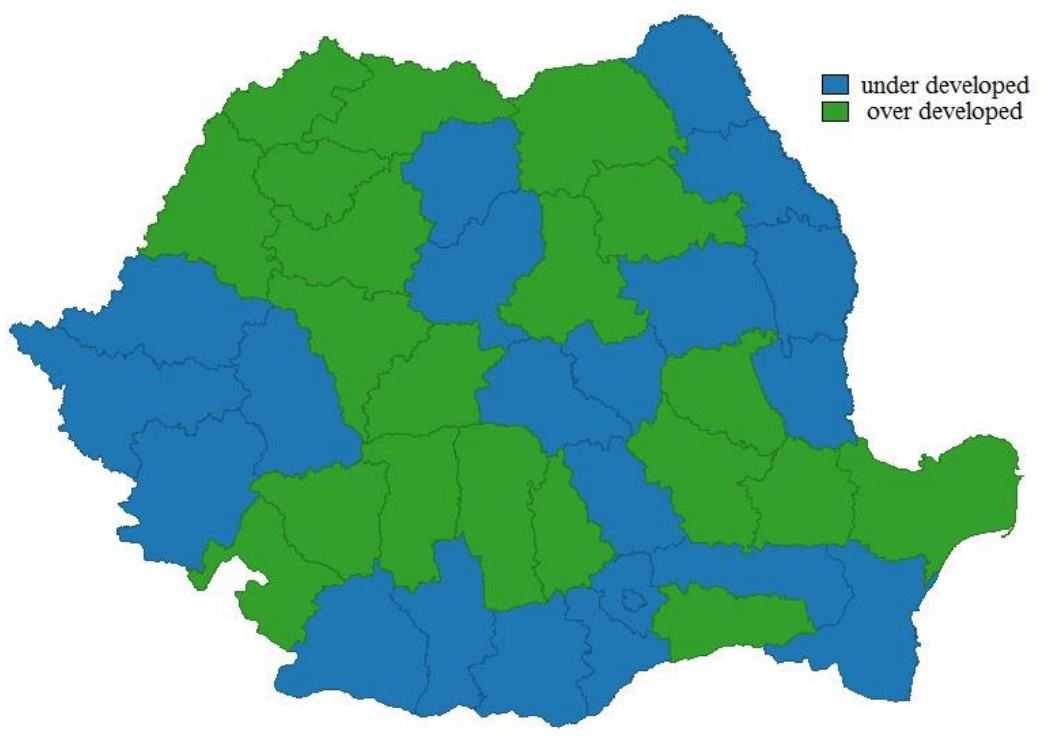

Figure no. 4: Mapping Romanian counties based on their performance index in 2016 (blue <1; green>1) 
The aim of our study was to determine the main drivers of rural tourism in Romania using PCA for mix data, which considers both numerical and non-numerical indicators, and to classify the counties based on their performance, using the cluster analysis. For conducting the PCA mix data analysis, the 3.4. R software has been used, while for the cluster analysis the $23^{\text {rd }}$ version of the SPSS software.

In the process of identification of the main drivers of rural tourism in Romania, the numerical indicators have been standardised. Analysing the internal consistency of potential items that will be included in the composite index using Cronbach Alpha coefficient, the empirical results revealed an acceptable level of internal consistency of items (average interitem covariance .1874384; number of items in the scale 12; scale reliability coefficient 0.7837 )

The empirical results revealed the existence of four principal components (Eigenvalue>1) which recovered almost $77.5 \%$ of the variance of original variables. (Table no. 2)

Table no. 2: The Eigenvalues and the variance from PCA mix data

\begin{tabular}{|c|c|c|c|}
\hline & Eigenvalue & Proportion & Cumulative \\
\hline $\operatorname{dim} 1$ & 4.61 & 38.48 & 38.48 \\
\hline $\operatorname{dim} 2$ & 2.31 & 19.27 & 57.75 \\
\hline $\operatorname{dim} 3$ & 1.35 & 11.25 & 69.00 \\
\hline $\operatorname{dim} 4$ & 1.02 & 8.50 & 77.50 \\
\hline $\operatorname{dim} 5$ & 0.685 & 5.70 & 83.20 \\
\hline $\operatorname{dim} 6$ & 0.602 & 5.02 & 88.22 \\
\hline $\operatorname{dim} 7$ & 0.588 & 4.90 & 93.12 \\
\hline $\operatorname{dim} 8$ & 0.413 & 3.44 & 96.56 \\
\hline $\operatorname{dim} 9$ & 0.334 & 2.79 & 99.35 \\
\hline $\operatorname{dim} 10$ & 0.066 & 0.55 & 99.85 \\
\hline $\operatorname{dim} 11$ & 0.007 & 0.09 & 99.94 \\
\hline $\operatorname{dim} 12$ & 0.002 & 0.06 & 100 \\
\hline
\end{tabular}

The first principal component recovered almost $38.48 \%$ of the total variance of original variables, followed by the second component who recovered another $19.27 \%$, summing up a total of $57.75 \%$ of total variance. The third component recovered another $11.25 \%$ of total variance while the fourth component recovered another $8.5 \%$ of total variance, summing a total of $77.5 \%$ of total variance. (Table no. 3)

Table no. 3: The empirical results of PCA after rotation

\begin{tabular}{|l|l|l|}
\hline & Variance & Proportion \\
\hline $\operatorname{dim} 1 . r o t$ & 4.34 & 36.18 \\
\hline $\operatorname{dim} 2 . r o t$ & 1.98 & 16.48 \\
\hline $\operatorname{dim} 3 . r o t$ & 1.82 & 15.19 \\
\hline $\operatorname{dim} 4 . r o t$ & 1.16 & 9.66 \\
\hline
\end{tabular}

To facilitate the interpretation of the principal components, the Varimax rotation procedure of axes has been used. Varimax rotation (Kaiser, 1958) is a very popular orthogonal rotation method for numerical data (that is for standard PCA). This simplifies the interpretation because, after a Varimax rotation, each original variable tends to be associated with one (or a small number) of factors, and each factor represents only a small number of variables. For mixed data type, Chavent et al. (2017) proposed an efficient Varimax type orthogonal rotation algorithm, based on an approach first developed by Kiers (1991). 
Analysing the matrix of principal components after rotation, the first component can be interpreted in terms of the number of rural agro-touristic guesthouses, touristic accommodation capacity of guesthouses, arrivals of tourists accommodated in agro-touristic guesthouses, overnight stays in the agro-touristic guesthouses. The second component is dominated by the categorical variable having airport nearby. The third principal component can be interpreted by being crossed by the Danube River. The last component is interpreted in terms of the number of dwellings stock at the end of the year in rural area. (Table no. 4) These represent main determinants of rural tourism.

Table no. 4: The matrix of principal components after rotation

\begin{tabular}{|c|l|l|l|l|}
\hline Z score (Code of Variable) & dim1.rot & dim2.rot & dim3.rot & dim4.rot \\
\hline z-Var1 & $\mathbf{0 . 9 4 7 8 2 3}$ & $3.03 \mathrm{E}-04$ & 0.007153 & 0.003963 \\
\hline z-Var2 & $\mathbf{0 . 9 6 5 0 8 7}$ & $9.33 \mathrm{E}-05$ & 0.008126 & 0.002713 \\
\hline z-Var3 & $\mathbf{0 . 9 4 4 6 0 9}$ & $7.11 \mathrm{E}-03$ & 0.007862 & 0.000481 \\
\hline z-Var4 & $\mathbf{0 . 9 6 1 4 8}$ & $3.33 \mathrm{E}-03$ & 0.002331 & 0.000979 \\
\hline z-Var5 & 0.051946 & $5.25 \mathrm{E}-01$ & 0.081465 & 0.03604 \\
\hline z-Var6 & 0.001327 & $5.01 \mathrm{E}-01$ & 0.195546 & 0.000692 \\
\hline z-Var7 & 0.00864 & $2.22 \mathrm{E}-01$ & 0.339745 & 0.003727 \\
\hline z-Var8 & 0.001188 & $7.49 \mathrm{E}-02$ & 0.210414 & 0.312608 \\
\hline z-Var9 & 0.022617 & $1.49 \mathrm{E}-03$ & 0.000231 & $\mathbf{0 . 7 7 3 8 5 1}$ \\
\hline z-Var10 & 0.32489 & $1.72 \mathrm{E}-02$ & 0.394997 & 0.012371 \\
\hline z-Var11 & 0.111649 & $1.52 \mathrm{E}-03$ & $\mathbf{0 . 5 6 8 9 2 3}$ & 0.001146 \\
\hline z-Var12 & 0.000277 & $\mathbf{6 . 2 3 E}-\mathbf{0 1}$ & 0.005949 & 0.010642 \\
\hline & & & & \\
\hline
\end{tabular}

To assess the quality of the results provided by the PCA mix data, the KMO and Bartlett's tests of sphericity revealed that the analysis could be considered adequate, since the value of $\mathrm{KMO}$ is 0.5 and the value of Bartlett test is statistically significant, having the probability smaller than the significance level of $1 \%$.

To compute the values of the potential composite index, the weights from the matrix of principal components after rotation have been determined using the proportion of variance recovered by each component in the total variance of all variables.

The non-standardized value of the rural tourism composite index is computed as follows:

Tourism_composite_index $=\frac{36.18}{77.51} \cdot \operatorname{dim} 1$ rot $+\frac{16.48}{77.51} \cdot \operatorname{dim} 2 r o t+\frac{15.19}{77.51} \cdot \operatorname{dim} 3 r o t+$

$\frac{9.66}{77.51} \cdot \operatorname{dim} 4$ rot

To facilitate the interpretation, the index has been rescaled using percentile rank, to take values between 0 and 100, where 0 represents the lowest potential for rural tourism and 100 the highest. 
Analysing the potential of rural tourism at county level in Romania in 2016, based on our composite index, the main poles of development are the counties of Suceava, Harghita, Brasov, Arges, Mures, Sibiu, and Cluj, with values of the index greater than 80 points. Referring to the NUTS level 2, the Center region is, by far, the leader in terms of potential for rural tourism; four out of the seven identified poles belong to this region, respectively Harghita, Brasov, Mures, and Sibiu. At the other end of the spectrum, there are counties like Botosani, Calarasi, Giurgiu, Ialomita, Olt, and Teleorman characterized by a very low potential for developing rural tourism activities. (Figure no. 5)

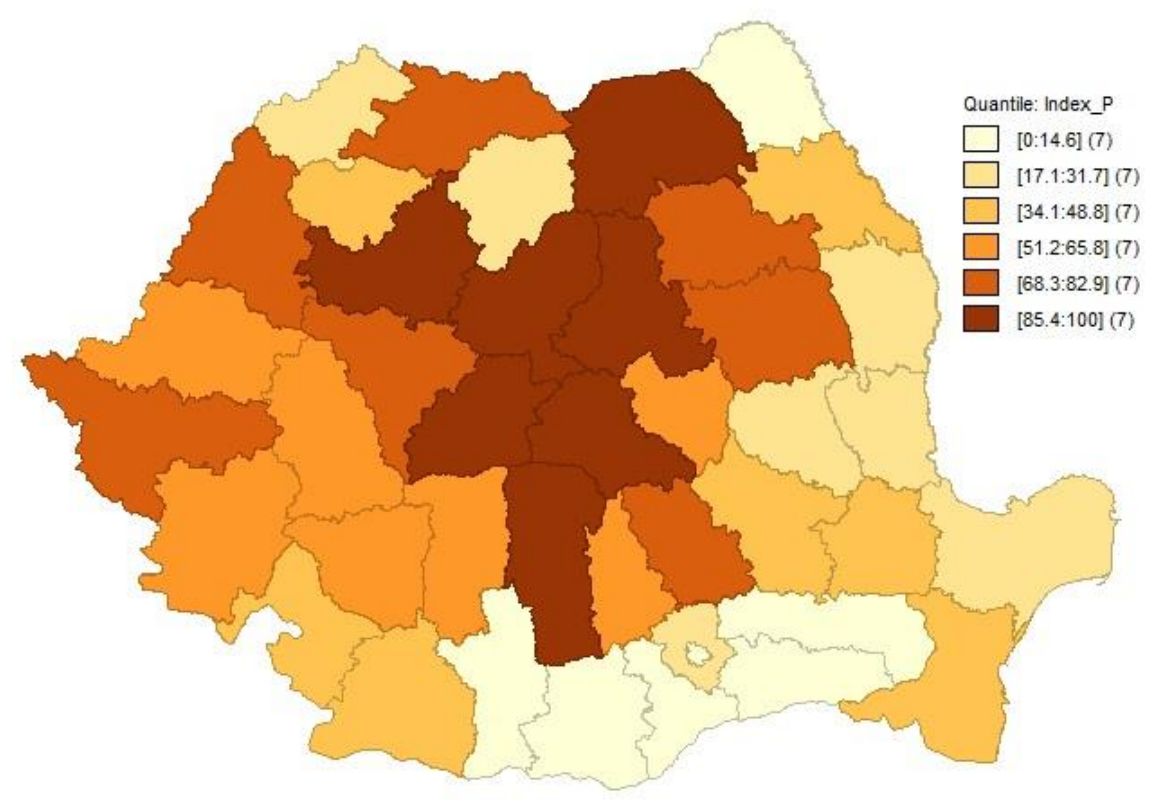

Figure no. 5: The potential index of rural tourism at county level in Romania in 2016

Even though the overall potential index provides a very clear hierarchy of the counties about this topic, the cluster analysis based on the four principal components highlights similarities between counties, grouping them into four main clusters (which step by step collapse in three, two and finally one single cluster). (Figure no. 6) 


AE The Regional Development of the Romanian Rural Tourism Sector

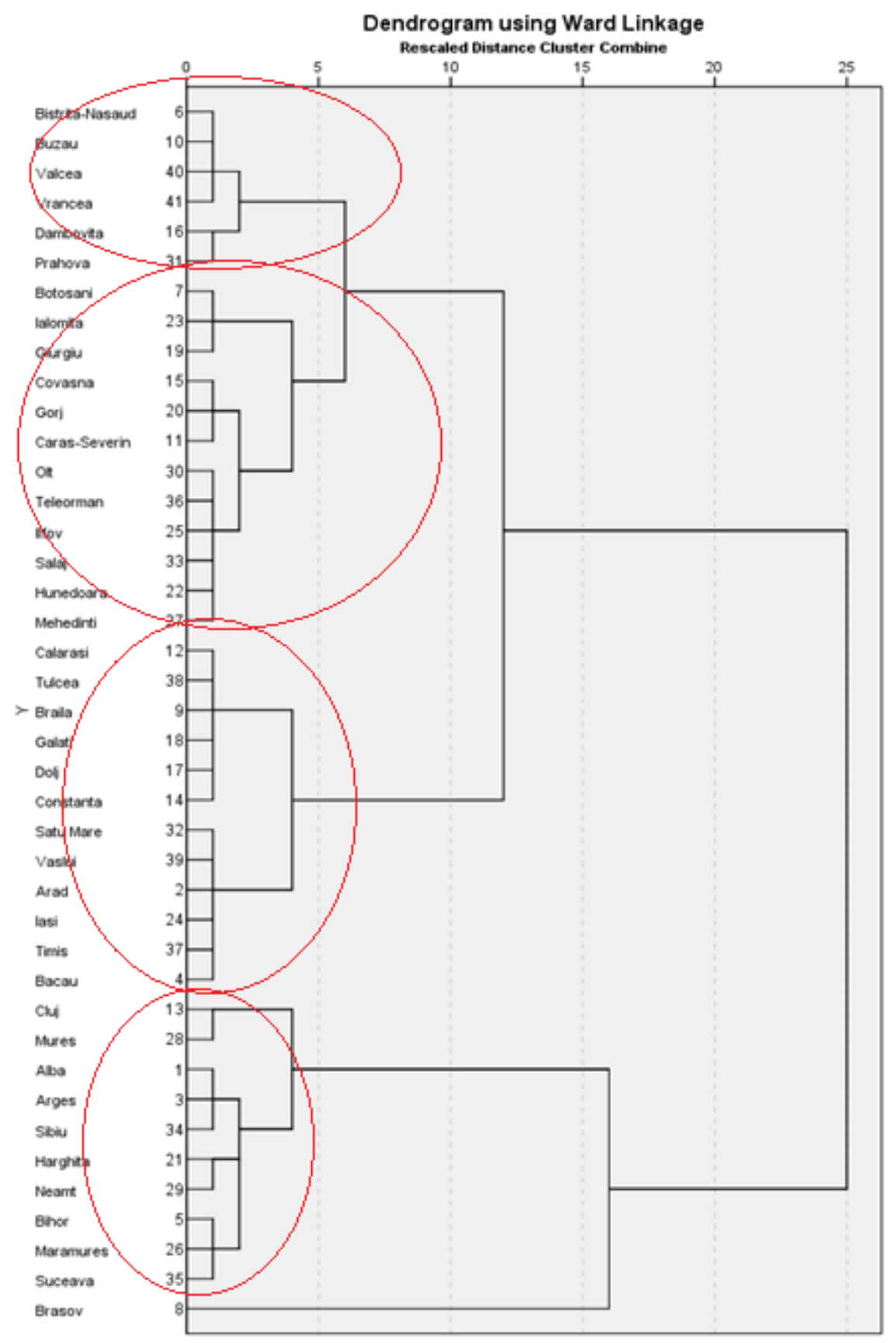

Figure no. 6: The empirical results of cluster analysis 


\section{Conclusions}

The main purpose of our paper was to analyse the development of the Romanian rural tourism from a regional perspective, highlighting its main determinants in 2016 using complex multidimensional analyses, namely the PCA for mix data (both quantitative and qualitative) and cluster analysis. One of the most important particularities of this paper was the application of the Chavent et al. (2017) PCA mixed data which has the advantage of considering both numerical and categorical variables.

Following this approach, we have computed one of the first composite indices measuring the sector of rural tourism, from the Romanian literature, allowing for the ranking of the counties based on the performances provided by the index. Through the proposed methodology, the index can also be used for identifying the main development opportunities for each region. The paper also offers the first mapping of rural tourism from a regional perspective, highlighting the counties with promising potential for developing rural tourism activities.

Based on the developed performance index, as a ratio between the percentage of rural overnight stays and the percentage of all overnight stays, at county level, from the national level, in 2016, Maramures, Suceava, Neamt, Harghita, Alba, Mehedinti, and Arges stood out as the most performant counties. However, other performant counties were located along the Carpathians (and in their vicinity), with a few exceptions for the South-Eastern part of the country, respectively: Tulcea, Braila and Calarasi counties. Another notable aspect revealed by the performance index was that almost half of the counties (20) had a better performance in the rural tourism sector than in the general tourism sector.

The empirical results of PCA mixed data revealed as the main determinants of rural tourism in Romania the following: the number of rural agro-touristic guesthouses, touristic accommodation capacity of guesthouses, arrivals of tourists accommodated in agro-touristic guesthouses, overnight stays in agro-touristic guesthouses, the presence of an airport nearby, the fact that the Danube River crosses particular counties, and the number of dwellings stock at the end of the year in rural area.

Analysing the potential of rural tourism at county level in Romania in 2016, based on our composite index, the main poles of development were the counties of Suceava, Harghita, Brasov, Arges, Mures, Sibiu, and Cluj, with values of the index greater than 80 points. On the other hand, there are counties like Botosani, Calarasi, Giurgiu, Ialomita, Olt, and Teleorman characterized by a very low potential for developing rural tourism activities.

Our paper puts forward valuable information in terms of rural tourism performance and potential for development, with a high scientific and practical impact. This may represent an important premise for future studies in the field, focusing on deepening the presented aspects to identify causes and solutions, on replicating the analysis for other future periods, etc.; both qualitative and quantitative research methods can be approached. Furthermore, considering our paper's practical implications, this may represent an important starting point in designing coherent policies meant at developing, improving, supporting, promoting, etc. rural tourism in Romania. 


\section{References}

Andrei, D.R., Gogonea, R.M., Zaharia, M. and Andrei, J.V., 2014. Is Romanian rural tourism sustainable? Revealing particularities. Sustainability, [e-journal] 6, pp. 8876-8888. doi:10.3390/su6128876

Chavent, M., Kuentz-Simonet, V., Labenne, A. and Saracco, J., 2017. Multivariate analysis of mixed data: The R package PCAmixdata. arXiv:1411.4911v1. [online] Available at: $<$ https://arxiv.org/abs/1411.4911> [Accessed 19 April 2018].

Davidescu, A. and Strat, V. A., 2014a. Coordinates of a New Romanian Regional PolicyIdentifying the Development Poles. A Case Study. Informatica Economica, 18(2), p.88.

Davidescu., A. and Strat, V.A., 2014b. An Empirical Analysis of Regional Poles from the Perspective of Romanian Sustainable Development. Procedia Economics and Finance, 10, pp. 114-124.

Eurostat, 2017. Eurostat regional yearbook 2017 edition. [online] Available at: <http://ec.europa.eu/eurostat/documents/3217494/8222062/KS-HA-17-001-EN-N.pdf/ eaebe7fa-0c80-45af-ab41-0f806c433763> [Accessed 18 April 2018].

Gooroochurn, N. and Sugiyarto, G., 2005. Competitiveness indicators in the travel and tourism industry. Tourism Economics, 11(1), pp.25-43.

Gritsay, M., Kulagina, E., Lukina, O. and Proncheva, O., 2018. Key indicators of clusterization potential in regional tourism. GeoJournal of Tourism and Geosites, 22(2), pp.297-306.

Grosu, R.M., 2015. Best practices in the field of returnee entrepreneurship. Amfiteatru Economic, 17(39), pp. 799-814.

Grosu, R.M. and Dinu, V., 2016. The migration process of Romanians to Andalusia, Spain. Focus on socio-economic implications. E \& M Ekonomie a Management, [e-journal] 19(2), pp. 21-36. DOI: 10.15240/tul/001/2016-2-002

Ildiko, I., Radulescu, C.V. and Bran, F., 2014. Romanian rural tourism: status and prospects by innovative organizational approaches. Journal of Tourism - Studies and Research in Tourism. [online] Available at: <http://www.revistadeturism.ro/rdt/article/viewFile/ 226/179> [Accessed 19 April 2018]

Imran, M. and Bhat, M.S., 2013. Identification of Tourist Potential Regions for Balanced Tourism Development in Pahalgam Tourist Destination of Kashmir Valley. Geography, 2(4), pp. 189-190.

Kaiser, H.F., 1958. The varimax criterion for analytic rotation in factor analysis. Psychometrika, 23(3), pp. 187-200.

Kiers, H. A., 1991. Hierarchical relations among three-way methods. Psychometrika, 56(3), pp. 449-470.

Mitrut, C., Constantin, D.L. and Gruiescu, M., 2009. Tourism potential and the diminishing of regional disparities in Romania. The Annals of the University of Oradea [online] Available at: <http://steconomiceuoradea.ro/anale/volume/2009/v2-economy-andbusiness-administration/25.pdf > [Accessed 19 September 2018].

Nestorosk, I., 2012. Identifying Tourism Potentials in Republic of Macedonia Through Regional Approach. Procedia - Social and Behavioral Sciences, 44, pp. 95-103. 
Nistoreanu, P., Ţigu, G., Popescu, D., Pădurean, M., Talpeş, A., Țală, M. and Condulescu, C., 2003. Ecoturism şi turism rural. Bucharest: ASE Publishing House.

Nistoreanu, P., 2007. Aprecieri asupra fenomenului touristic rural. (Appreciations on the rural touristic phenomenon). Revista de turism, iss. 3, pp. 16-23.

NIS, 2016. Tempo Online [online] Available at: <http://statistici.insse.ro/shop/?lang=ro> [Accessed 9 April 2017].

Nunnally, J. C., 1978. Psychometric theory. $2^{\text {nd }}$ ed. New York : McGraw-Hill

OECD, 2008. Handbook on constructing composite indicators: methodology and user guide. [online] Available at: <http://www.oecd.org/els/soc/handbookonconstructingcomposite indicatorsmethodologyanduserguide.htm> [Accessed 15 April 2017]

Ogarlaci, M., 2014. Rural tourism sustainable development in Hungary and Romania. Quaestus Multidisciplinary Research Journal, [online] Available at: <http://www.quaestus.ro/wp-content/uploads/2012/03/ogarlaci4.pdf> [Accessed 2 March 2018].

Oliveira, E., 2014. The tourism potential of Northern Portugal and its relevance for a regional branding strategy. Advances in Hospitality and Tourism Research, 2(2), pp. 54-78.

Pascariu, G.C. and Ţigănaşu, R., 2014. Tourism and sustainable regional development in Romania and France: an approach from the perspective of new economic geography. Amfiteatru Economic, 16(Special No. 8), pp. 1089-1109

Peypoch, N. and Solonandrasana, B., 2008. Aggregate efficiency and productivity analysis in the tourism industry. Tourism Economics, 14(1), pp. 45-56.

Pop, C., Coros, M.M. and Balint, C., 2017. Romanian Rural Tourism: a Survey of Accommodation Facilities. Studia UBB Negotia [e-journal], 62(2(June)), pp.71- 126. doi:10.24193/subbnegotia.2017.2.05.

UNCTAD, 2012. World Investment Report 2012. [online] Available at: <http://unctad.org/en/PublicationsLibrary/wir2012_embargoed_en.pdf> [Accessed 15 April 20171

Thelen, T., 2015. Care of the elderly, migration, community: explorations from rural Romania. In: A. Erdmute and H. Drotbohm, eds. 2015. Anthropological perspectives on care. Work, kinship, and the life-course. New York, USA: Palgrave Macmillan, pp. 137-156.

Zamfir, A.M., Mocanu, C. and Grigorescu, A., 2018. Resilient Entrepreneurship among European Higher Education Graduates. Sustainability, 10(8), p. 2594. 